\title{
Vectors of psychology development in the transitive period as a methodological basis for identifying trends in the development of psychological education
}

\author{
Alexandra Kriulina* \\ Kursk state University, Institute of social innovations and technologies, industrial- \\ pedagogical faculty, 305000 Kursk, Russia
}

\begin{abstract}
The author sticks to the opinion of psychological education quality dependence upon the methodological knowledge of psychology teachers who practice professional training as psychologists. In order to enrich their methodological knowledge sixteen vectors of modern psychology development are generalized. The resulting set is proposed to be considered as a methodological basis for identifying promising trends in the development of modern psychological education. Psychology in the transitive period is evidently qualified by the author as a transitive field of science, which has all the signs of transitivity. The author's hypothesis about one of the possible ways to identify trends in the development of modern psychological education is proposed and justified. The author comments on two trends and three problems that are most important for the quality of psychological education. Author's means for the solution of the discussed problems are offered here.
\end{abstract}

\section{Introduction}

In the last third of the 20th century psychology managed to survive the pathos period of methodological works euphoria. Secret methodological seminars of G. P. Shchedrovitsky and battles of the methodology in formal scientific seminars in PI RAO gathered a huge audience hungry for live communication with the methodology guru. The teachers of the faculty of Psychology of Moscow state University enjoyed popular methodological seminars under the guidance of A. N. Leontiev "Philosophical Problems of Psychology". Initially, the seminars were aimed at teachers, but graduate students and students were allowed to attend them. Since 1969 the yearbooks of the "System Research" publications on the methodology of different sciences, including psychology, started to be published. The level of methodological awareness of psychologists at that time was quite high, as it was based on the methodological works of officially recognized authoritative scientists. A new round of increased interest in the methodology of psychology occurred at the beginning of the 21 st century. Since 2007 the specialized journal "Methodology and History of

\footnotetext{
* Corresponding author: anitim@list.ru
} 
Psychology" has been published. The diversity of scientific sources gives hope for the opportunity to solve the problem fixed in the title of the article.

Let's try to generalize, to cover with one look (as far as it is possible) the theoretical directions of its development revealed by psychological methodologies and really existing in the transitive period. This is the first challenge to be addressed in this study. It is inextricably linked with the second task: to identify promising areas of development of psychology, explicitly or implicitly voiced by authoritative psychologists of Russia in an interview organized by T. A. Nestik, doctor of psychological sciences, head of the laboratory of social and economic psychology of the Institute of psychology of RAS [1]. The final, third task of the study is to substantiate the relevance of the vectors of development of theoretical psychology with trends in the development of psychological education, which would serve as the basis for their identification.

Let's start with the content characteristics of the concept of "transitivity". It is important to note that the notion of "transitivity" is most fully described by M. S. Guseltseva. First, it considers it in one row with other challenges of our time, significant both for psychology and for society as a whole: globalization, informatization, transitivity, evolutionary increase in complexity and diversity (the latter is also manifested as a trend of personalization). Secondly, it gives their understanding of its content in comparison with the variant proposed by the author of this concept: "Transitivity is a concept in psychology introduced T.D. Marcinkowskaya, it brings variability and uncertainty. However, I would present this trend more broadly, denoting it as a general state of trans-complex phenomena, united by the current changes: the transformation of the life world of the subject, the movement of transdisciplinarity (including the displacement and mixing of knowledge, the erosion of disciplinary boundaries), flows from transgender to transhumanism" [2, p. 223-224]. Having determined the content of the concept of "transitivity", it is logical to turn to the solution of the first problem identified at the beginning of the article.

Dichotomous judgments (hereinafter - dichotomies) are firmly established in the pages of psychological monographs and textbooks on methodological problems. Such dichotomies as "object - subject", "external - internal", "theoretical psychology - practical psychology" and others, used by different authors for a long time, have become commonplace. In the textbook of T. V. Kornilova and S. A. Smirnov such dichotomies as natural-scientific and humanitarian paradigms, of classical and of non-classical psychology, morphological and dynamic paradigms, descriptive and explanatory psychology are analyzed [3]. Other authors use the dichotomy to refer to the motion vector of the emerging scientific psychology. This technique was used by V. V. Znakov in the title of his methodological article: from the psychology of the subject to the psychology of human existence [4].

\section{Results and discussion}

D. A. Leontiev to refer to the non-classical vector of development of psychology consistently listed and described seven directions of development of psychological science, formulated in the form of dichotomies. Here is a complete list of them, numbered in the subsequent analysis of directions for ease of reference [5]:

1) from the search for knowledge to social construction

2) from monologue to dialogism,

3) from an isolated individual to the life world,

4) from determinism to self-determination,

5) from potentialism to existentialism,

6) from quantitative to qualitative approach,

7) ascertaining the strategy to be effective. 
The seven directions are not exhaustive, as the author himself drew attention to. The basis for the continuation of this list can serve as the work of other scientists, psychologists, actively developing methodological problems of psychology. Turning to their works, which contain the development of the right part of the dichotomies, we formulate five more areas that could complement the already listed. It should be noted that all twelve directions are important for the characterization of the status of psychology in the transition period of development for society. Numbering will continue:

8) from monoparadigmatic to the multi-paradigm character (Etc. Marcinkowska, 2007), or multiparadigmatic (T. V. Kornilova, 2007) or methodological pluralism (S. D. Smirnov, 2007);

9) from interdisciplinary synthesis and integration of psychological knowledge within the framework of psychology itself to interdisciplinary synthesis (A. A. Kriulina, 1996; A. L. Zhuravlev, 2007) or transdisciplinarity (M. S. Guseltseva);

10) from tactical psychology to strategic psychology of globalization, developed by a group of political psychologists, headed by Professor A. I. Yuriev [6];

11) from micropsychology to macropsychology [7];

12) from nomothetic to idiographic [8].

It is reasonable to assume that all twelve directions are not an exhaustive inventory of methodological vectors. A complete definition of it is perhaps the task for the nearest future. It seems to be as important in the context of the problems discussed as the task of identifying how the poles of scientific study mentioned in the dichotomies relate to each other? It is easy to see from the content of the contexts in which the dichotomies are presented that they are generally regarded as opposing judgments, that is, their opposition takes place. In some cases, the opposition is expressed explicitly when using a tabular version of the opposition of the two approaches, theories, concepts, methods. At the same time, the presence of the compared features increases their opposition. In other cases, when the dichotomy is contained in the subheadings of the text, where the objects of judgment being compared are connected by the conjunction "and", the opposition is less pronounced, although it is implied by the authors of the texts. The contrast is almost absent if the objects of analysis are connected by the prepositions "from" and "to", as in the previously cited work of D. Leontiev. In this case, they are referred to as the initial stage of the state of theory in the development of psychology and the stage at which the efforts of researchers should be aimed.

Note that opposition is not the only form of relations between the poles of vectors. There are some others. For example, at the 29th International psychological Congress the possibility of coexistence of different research paradigms was discussed, it was noted that there had been a tendency to search for points of their mutual agreement. They also discussed the possibility of combining qualitative and quantitative analysis [9]. Prologue relationship of coexistence is an ingenious foresight of the author of the terms "nomothetic and idiography" V. Windelband. He argued back in 1984 that "any event, any phenomenon can be considered in double optics: as a particularly private and unique and under the sign of uniformity" [10, p. 174].

Psychological studies of the 20th century try to find a real confirmation of the statement expressed by V. Windelband in the 19th century in relation to scientific knowledge in general. We study the possibility of coexistence nomothetic and idiographic, two approaches that belong to the poles of the twelfth vector. To substantiate this statement, we turn to the works of A. R. Luria. At the time, he carried out two longitudinal researches. Both were aimed at the study of unique psychological phenomena. In one of them the phenomenal memory of the mnemonist Shereshevsky (further - sh., as in the author's text A. R. Luria) was investigated. In another - the object of the study was the history of one injury, described first in the diaries of the wounded L. Zasetsky. Both studies were reflected 
in two well-known monographs by A. R. Luria. The content of both monographs suggests that both studies were performed from the perspective of idiography, although the term was not used by the author $[11,12]$. A. R. Luria hoped that the approach chosen by him deserves the followers, and if they were found, "this would be the beginning of a specific psychology that would not lose its scientific character" [11, p. 6].

The first study is connected with "A Small Book about Big Memory". For 30 years he had been observing $S h$. (as he called the hero of his book), trying to give a qualitative analysis of his unusual memory. He compared its features with those obtained in other studies of memory, performed by psychologists from the standpoint of nomothetic. At the same time he investigated the influence of his extraordinary memory upon the efficiency of $S h$ 's mental activity in its different aspects, upon his personal unique characteristics and his behavior in everyday life. Thus, the readers of a small scientific masterpiece perceived the life of a person with a phenomenal memory as a unique "natural experiment", carefully and in the entirety of its life manifestations described by the great researcher A. R. Luria.

Analyzing the diary entries, which were kept by the hero of his second book for a quarter of a century, A. R. Luria reflected on the painful struggle of L. Zasetsky with the disease and his heroic struggle for life. The efforts of the hero of the book "Lost and Returned World" were reflected in his handwritten texts, the total volume of which was 3000 pages. An example of this book is a detailed illustration of the main task of the idiographic approach. It is to "provide each subject with an opportunity to speak his own language, to preserve the meanings that support the lives of specific people in this world, and to fix these meanings and subjective experiences through relatively unstructured, informal, projective and interpretive methods" [13, p. 225]. It was L. Zasetsky who was the one who told all about his life problems with his own language. And only then his meanings manifested in their original form in the diaries were transferred to the book. In three digressions A. R. Luria in the language of science, but understandable to a wide audience provided them with his comments.

His style of presentation in the two analyzed books A. R. Luria referred to the so-called "romantic" science, which he believed should be revived. Books written in this style, he considered "biographical", but not easier. At the same time, he was not an alien to analytical science and to the classical academic language of its description. Such books of A. R. Luria as "Higher Cortical Functions", "Language and Consciousness" and many others, which brought him fame and appreciation not only in Russia but also in the world science, were written in classical style. Both written styles of his books he rightly considered complementary.

Let us return to the concepts and note that the notion of "coexistence", it corresponds to a special view of the process of manifestation of different directions of psychological science development in the transitional period of society development. Analyzing the polar approaches, theories, concepts, methods, it is advisable to consider them as complementary to each other, as their representatives in different ways seek to obtain productive knowledge about the phenomenon under study. Only their synthesis can provide a holistic knowledge of the examined phenomenon, the final result to which researchers were striving for. The concept of "integrity" came to the world psychology with Gestalt psychology and the Leipzig school. The methodological significance of this concept V. A. Hansen understood in the 20th century, when he proposed and justified the need to apply the principle of integrity in Russian psychology [14]. Only in the 21 st century modern psychologists begin to treat the principle of integrity with due respect and interest to. At the same time, there are concrete attempts to integrate psychological knowledge into academic social and practical psychology. Their detailed analysis was put into practice in the scientific research of integration efforts by different psychologists [15]. 
It is natural to assume that in a transitive society science has all the signs of transitivity. Comparing psychological science with the transitive society in which it exists, it is appropriate to take advantage of the triad of features defined by T. D. Marzinkovskaya: multiplicity, variability and uncertainty. For example, psychology is also characterized by multiplicity, as well as a transitive society itself. In particular, this plurality is observed in relation to the types of research. We can easily find studies performed in a strict classical style. At the same time, there are non-classical and even post-non-classical studies. And this is a normal state for a constantly developing scientific field.

The variability of psychology development in the transitive period for society reflects the identified set of twelve vectors. Continuing the characteristics of variability, it is advisable to add to a compilation of earlier vectors in the development of psychology, its perspective directions contained in explicit and implicit form in an interview with Russian psychologists, carried out T. A. Nestic:

1) from the refinement and specialization of theoretical psychological research to the integration of their authors with other psychologists representing its different areas, with scientists from other Humanities (and possibly natural);

2) from isolation and isolation of Russian psychology and Russian psychologists to integration into the world community of psychologists;

3 ) from purely academic language of description of scientific results to other ways of presentation and interpretation of empirical data.

4) from the deficit line in psychotherapy to the self-actualization line [1].

It is pleasant to realize that the priority problem discussed in the interview was the necessity to revive interdisciplinary psychological research. Almost every participant of the interview touched upon some aspects of this problem during the discussion. It is about the revival should be discussed, as attempts of interdisciplinary research in the history of psychology existed. This was said in an interview with T. D. Martsinkovskaya, referring to the experience of the State Academy of Arts, in which psychologists, philosophers, cultural scientists, biologists, and physiologists of the time jointly developed human problem. Closing its doors in 1927, the interdisciplinary studies went out. A new wave of interest in interdisciplinary research was observed during the establishment of the Institute of Human Sciences, which existed for only twelve years in the period from 1992 to 20004. The subject of interdisciplinary studies was the human consciousness, their behavior in work and extreme situations, the prospects of personal development. The possibility of a revival of interdisciplinary research contains the prediction of the future of science in an interview with A. E. Voiskounsky, Professor of Moscow State University. He considers it in the emergence of the Science of Human Being, covering biology, and experimental medicine, and biochemistry, and mathematics, and computer science, and physics. In his interview about the future of psychology, HSE Professor V. A. Klyucharev called its interdisciplinary dimension the main challenge for psychology [1].

An indicator of uncertainty in modern psychology may serve the difficulties experienced by some psychologists in answering the questions of T. A. Nestik about the future of psychology, the promising directions of its development in the Russian and world scientific communities. This fact is ambiguous, as it may indicate not only the low level of scientists' possession of the time perspective, but also some caution in forecasting the future.

\section{Summary}

1. In the transitive period of society development, psychological science can also be considered as transitive, because it is endowed with all the signs of transitivity: multiplicity, variability, uncertainty. 
2. The study summarizes and presents a set of sixteen vectors of modern psychology, proposed by different methodologies of psychology. This set is a double argument, confirming both the multiplicity and variability of psychological science.

3 . The set of generalized vectors of development of modern psychology should be realized as a methodological basis for identifying trends in the development of psychological education by projecting them on the content of psychological education. The resulting projections coincide with the vectors and problems of psychology development only in name, but the content is significantly different from them.

4. Three of the most important problems of the projection of the psychological education were identified and commented on here: the integrity of the final knowledge of studentspsychologists, the availability of language teaching and the trinity of the professional roles of teachers of psychology at the University.

\section{References}

1. Interview on the future of psychology. URL: http://www.ipras.ru/cntnt/rus/media/onlayn-bibliote/intervu-o-budush.html

2. SOC and economy. the course of studies, 3, 4 (12) (2018)

3. T.V. Kornilova, S.A. Smirnov, Methodological foundations of psychology (Peter, St. Petersburg, 2009)

4. W.W. Znakov, Theory and methodology of psychology. Post-non-classical perspective (Institute of Psychology RAS, Moscow 2007)

5. D.A. Leontiev, Theory and methodology of psychology. Post-non-classical perspective (Institute of Psychology RAS, Moscow 2007)

6. Strategic psychology of globalization. Psychology of human capital (Logos, St. Petersburg, 2006)

7. A.V. Yurevich, D. V. Ushakov, Vopr. The course of studies, 4, 3-15 (2007)

8. O.G. Noskova, Methodol. and history of psycho, 3, 145-152 (2008)

9. B.B. Velichkovsky, Problems of experimental psychology at the XXIX International psychological Congress. the course of studies., 1, 112-116 (2009)

10. J.Reale, D. Antiseri, Western philosophy from its origins to the present day. From romanticism to the present day (Pnevma Publishing House, St. Petersburg, 2003)

11. A.R. Luria, Small book about big memory (Mind of the mnemonist) (Eidos, Moscow, 1994)

12. A.R. Luria, The Lost and returned world (Univer, Moscow, 1971)

13. R. Corsini, A. Auerbach Psychological encyclopedia (Peter, SPb, 2006)

14. V.A. Hansen, System descriptions in psychology (Publishing house Leningr. Univ, Leningrad, 1984)

15. A. A. Kriulina, The Principle of integrity as a methodological vector of integration of socio-psychological information. Social and economic psychology. Part 1: Status and prospects of research (Institute of psychology RAS, Moscow, 2018) 